\section{Correspondence on 'Incidence trend of five common musculoskeletal disorders from 1990 to 2017 at the global, regional and national level: results from the global burden of disease study 2017'}

With great interest, we have read the recent article 'Incidence trend of five common musculoskeletal disorders from 1990 to 2017 at the global, regional and national level: results from the global burden of disease study 2017' by professor Jin et al ${ }^{1}$ which aimed to further estimate the cause-specific prevalence of musculoskeletal (MSK) disorders and their trend from a global, regional and national prospective. The authors concluded that the age-standardised incidence rate (ASR) of MSK disorders has been decreasing in mainly the high-middle sociodemographic index regions, however, for rheumatoid arthrits, osteoarthritis and gout specifically, these have remained increasing, which is identical with previous research. ${ }^{2-4}$ This study indeed built a solid foundation of future government policies and further follow-up studies for the specific MSK disorders, an important cause of disability. ${ }^{5}$ Nevertheless, some methodological issues of this study must be reconsidered.

First and foremost, we are curious about what exact occupations did the authors modify during the study, and how were those selected occupations classified? In order to compare the differences between occupations during the analysis, is it possible to divide the worldwide patients into groups according to their occupations in the first place, instead of separating them based on their high or low human development index . Furthermore, the article mentioned that only the patients from high HDI countries have been paired with major risk factors such as social factors and occupational risks. However, we would like to know why did the authors chose to omit these risk factors when it comes to low HDI countries, since we consider occupations still play a significant role in those countries with low HDI.

In terms of population and age, through demographic and sociological analysis, we can estimate the future population changes and the proportion of each age. Furthermore, this research has analysed the development trends of the five major causes of MSK disease for each age, and the ageing population do increase the burden of MSK disorder. ${ }^{6}$ If we can use these two conditions to estimate the global fashion trends of the five MSK causes in the future, which can draw more attention and prevention of high-risk causes. Figure 4B,C points out the correlation between estimated annual percentage change and baseline ASR plus the correlation between EAPCs and HDI. However, some points are far away from the regression line in the chart. For example, in figure 4B, some high ASR places' EAPCs are still very high. Plus, there are especially low EAPCs places in figure 4C. Which countries are presented in this chart? Are there any special features in their demographic composition (age, gender, occupation etc)? Moreover, it would be better if we can find out causes of the gap.

Finally, there are a few minor issues to discuss. First, the article mentioned the unavailable HDI data of Taiwan. However, we found that Taiwan's HDI in 2019 was 0.911 according to National Statistics. We hope that this data can help your analysis. Furthermore, figure $1 \mathrm{~B}$ indicates the difference in the global change of MSK cases. The most significant growth areas in recent years are mainly in Africa and South America, but the medical care in the region is relatively behind other countries, the increase of cases in these areas may be a result of the popularisation of medical care which lead to an increase in the detection rate. Though, it may lead to errors. Finally, in figure 4A, the blue icon is marked as MSK. Nevertheless, according to the description in the chart of the subject and text content, this icon is more appropriate to be marked as low back pain.

In summary, if more attention and details of (1) exact occupations; (2) population and age; (3) a few minor issues be taken into consideration, this may make this study more comprehensive based on this invaluable database.

Ping-Hao Chiang $\odot,{ }^{1}$ Po-Chung Ju, ${ }^{1,2}$ Yun-Chi Chiang, ${ }^{1}$ James Cheng-Chung Wei $\odot^{3,4,5}$

${ }^{1} S c h o o l$ of Medicine, Chung Shan Medical University, Taichung, Taiwan ${ }^{2}$ Department of Psychiatry, Chung Shan Medicl University, Taichung, Taiwan

${ }^{3}$ Institute of Medicine, Chung Shan Medical University, Taichung, Taiwan

${ }^{4}$ Department of Allergy, Immunology \& Rheumatology, Chung Shan Medical University Hospital, Taichung, Taiwan

${ }^{5}$ Graduate Institute of Integrated Medicine, China Medical University, Taichung, Taiwan

Correspondence to Dr James Cheng-Chung Wei, Institute of Medicine, Chung Shan Medical University, Taichung 40201, Taiwan; jccwei@gmail.com

Contributors $\mathrm{P}-\mathrm{CJ}$ and JCCW are responsible for critical comment and revision. $\mathrm{P}-\mathrm{HC}$ and $\mathrm{Y}-\mathrm{CC}$ are responsible for manuscript preparation. PC-J and P-HC contribute equally.

Funding The authors have not declared a specific grant for this research from any funding agency in the public, commercial or not-for-profit sectors.

Competing interests None declared.

Patient and public involvement Patients and/or the public were not involved in the design, or conduct, or reporting, or dissemination plans of this research.

Patient consent for publication Not required.

Provenance and peer review Not commissioned; internally peer reviewed.

(c) Author(s) (or their employer(s)) 2020. No commercial re-use. See rights and permissions. Published by BMJ.

$\mathrm{P}-\mathrm{HC}$ and $\mathrm{P}-\mathrm{CJ}$ contributed equally.

\section{Check for updates}

To cite Chiang P-H, Ju P-C, Chiang Y-C, et al. Ann Rheum Dis Epub ahead of print: [please include Day Month Year]. doi:10.1136/annrheumdis-2020-219522

Received 16 November 2020

Accepted 17 November 2020

\section{Linked}

- http://dx.doi.org/10.1136/annrheumdis-2020-219536

Ann Rheum Dis 2020;0:1. doi:10.1136/annrheumdis-2020-219522

\section{ORCID iDs}

Ping-Hao Chiang http://orcid.org/0000-0002-0512-477X

James Cheng-Chung Wei http://orcid.org/0000-0003-0310-2769

\section{REFERENCES}

1 Jin $\mathrm{Z}$, Wang $\mathrm{D}$, Zhang $\mathrm{H}$, et al. Incidence trend of five common musculoskeletal disorders from 1990 to 2017 at the global, regional and national level: results from the global burden of disease study 2017. Ann Rheum Dis 2020;79:1014-22.

2 Cross M, Smith E, Hoy D, et al. The global burden of rheumatoid arthritis: estimates from the global burden of disease 2010 study. Ann Rheum Dis 2014;73:1316-22.

3 Safiri S, Kolahi AA, Hoy D, et al. Global, regional and national burden of rheumatoid arthritis 1990-2017: a systematic analysis of the global burden of disease study 2017. Ann Rheum Dis 2019;78:1463-71.

4 Safiri S, Kolahi A-A, Smith E, et al. Global, regional and national burden of osteoarthritis 1990-2017: a systematic analysis of the global burden of disease study 2017. Ann Rheum Dis 2020;79:819-28.

5 Clark P, Denova-Gutiérrez E, Razo C, et al. The burden of musculoskeletal disorders in Mexico at national and state level, 1990-2016: estimates from the global burden of disease study 2016. Osteoporos Int 2018;29:2745-60.

6 Smith E, Hoy DG, Cross M, et al. The global burden of other musculoskeletal disorders: estimates from the global burden of disease 2010 study. Ann Rheum Dis 2014;73:1462-9. 